УДК 615.322/582.951.6/543.544/543.51

\title{
СРАВНИТЕЛЬНОЕ ИЗУЧЕНИЕ ЛИПОФИЛЬНЫХ ВЕЩЕСТВ РАСТЕНИЙ РОДА EUPHRASIA L.
}

\author{
(C) О.А. Кроткова, Т.В. Бомбела", В.М. Петриченко
}

Пермская государственная фрармацевтическая академия, ул. Полевая, 2, Пермь, 614990 (Россия), e-mail: tatyana.bombela@yandex.ru

Методом газожидкостной хроматографии (ГХ/МС) изучен состав липофильных веществ, извлекаемых гексаном, в траве E. officinalis L., E. tatarica Fisch., E. stricta D. Wolff. ex J.F. Lehm., E. x reuteri Wettst., E. × murbeckii Wettst., E. brevipila Burnat et Gremli, E. parviflora Schag., произрастающих в Пермском крае. Идентифицированы: октадекан, нонадекан, эйкозан, гексакозан, гептакозан, октакозан, нонакозан, 2-нонакозанол, неофитадиен, лауриновый, миристиновый альдегиды, пальмитиновая, стеариновая, линолевая, линоленовая, олеиновая кислоты, $\gamma$-ситостерол, сквален, гексагидрофарнезилацетон, фталевая кислота. Доминирующими являются высшие алканы, $\gamma$-ситостерол и сквален. Жирные кислоты и их альдегиды обнаружены в небольшом количестве во всех исследованных видах.

Ключевые слова: ГХ/МС, липофильные вещества, Euphrasia.

\section{Введение}

Род Очанка (Euphrasia L.), сем. норичниковые (Scrophulariaceae Juss.) представлен однолетними травянистыми полупаразитическими растениями, широко распространенными в умеренных зонах обоих полушарий [1]. Растения рода Очанка давно и эффективно применяются в народной медицине, гомеопатии, используются для получения биологически активных добавок, включены в фармакопеи ряда стран Западной Европы [2-4]. Установлено, что экстракционные препараты из видов рода Очанка обладают фармакологической активностью и проявляют противовоспалительное, антиоксидантное, гипотензивное и антимикробное действие, сочетающееся с низкой токсичностью $[5,6]$. Скрининговые исследования растений семейства норичниковые показали, что липофильная фракция травы очанки коротковолосистой обладает высоким уровнем противолейкемической активности [7].

В последние годы значительно возрос научно-практический интерес к липофильным веществам природного происхождения, что связано с установлением широкого спектра их фармакологической активности. Например, одной из групп биологически активных веществ, проявляющих антисклеротическое действие, являются жирные кислоты и прежде всего непредельные. Такие непредельные кислоты, как линоленовая и линолевая, образуются только в растениях и входят в состав эссенциальных фосфолипидов $[8,9]$. Фитостерины естественным образом присутствуют в растениях, структурно подобны холестерину и, являясь его антагонистами, обладают антиатеросклеротической, онкопрофилактической, антиоксидантной и иммуностимулирующей активностью [10]. Кроме того, исследование липофильных веществ является актуальной задачей, так как позволяет выявить химические вещества, которые обусловливают терапевтические свойства растений. Сведений о составе липофильных веществ растений рода Очанка в доступной литера-

Бомбела Татьяна Владимировна - доцент кафедры фармакогнозии с курсом ботаники, кандидат фармацевтических наук, е-mail: tatyana.bombela@yandex.ru Кроткова Ольга Александровна - ассистент кафедры фармакогнозии с курсом ботаники, e-mail: krotkovaoa@yandex.ru туре не обнаружено.

Цель настоящей работы - сравнительное изучение компонентного состава и количественного содержания липофильных веществ семи видов рода Euphrasia, произрастающих в Пермском крае.

\footnotetext{
* Автор, с которым следует вести переписку.
} 


\section{Экспериментальная часть}

Материалом исследования служила надземная часть с корнями семи видов рода Очанка - Euphrasia L., сем. Норичниковые - Scrophulariaceae Juss.: E. officinalis L. - о. лекарственная; E. tatarica Fisch. ex. Spreng. - о. татарская; E. stricta D. Wolff ex. J.F. Lehm. - о. прямая; E. × reuteri Wettst. - o. Pейтера; E. × murbeckii Wettst. - о. Мурбека; E. brevipila Burn. et Gremli - о. коротковолосистая; E. parviflora Schag. - о. мелкоцветная. Образцы заготовляли в фазу цветения - начало плодоношения в период с 2007 по 2008 г. в Пермском крае (табл. 1). Сырье сушили до сухого состояния на воздухе в тени.

Приготовление извлечения для хроматографирования: 1,0 г измельченного сырья заливали гексаном в соотношении $1: 10$ и нагревали с обратным холодильником на кипящей водяной бане в течение 60 мин. Извлечение охлаждали до комнатной температуры и фильтровали через бумажный фильтр в мерную колбу вместимостью 10 мл, доводили объем раствора до метки гексаном и перемешивали.

Анализ липофильных веществ проводили на газовом хроматографе Hewlett - Packard 5890/II (CША) с квадрупольным масс-спектрометром (MS) (HP MSD 5971). Условия хроматографического разделения: колонка кварцевая HР-5 (5\% фенильных групп) длинной 30 м и внутренним диаметром 0,25 мм, толщиной пленки неподвижной фазы 0,25 мкм, газ-носитель гелий с постоянным потоком 1 мл/мин. Температура испарителя $250{ }^{\circ} \mathrm{C}$, источника ионов 170 , интерфейса между ГХ и МС детектора $280{ }^{\circ} \mathrm{C}$. Скорость сканирования 1,2 скан/сдля области 45-450 а.е.м. Проба 1 мкл.

Компоненты липофильного извлечения идентифицировали путем сравнения времени удерживания и полных масс-спектров с соответствующими данными библиотеки Wiley275 и NIST98. Содержание индивидуальных веществ вычисляли по площади пиков, без использования градуировочных коэффициентов с программированным автоматическим интегрированием. Учитывали компоненты с концентрацией выше $0,005 \%$ и вероятностью совпадения масс-спектров более $80 \%$. Повторность проведенных определений - трехкратная.

Таблица 1. Образцы растений рода Euphrasia L.

\begin{tabular}{c|l|c|c}
\hline № & \multicolumn{1}{|c|}{ Виды } & Место сбора & Дата сбора \\
\hline 1 & E. officinalis & Пермский край, Кудымкарский р-н, д. Сидорово, суходольный луг & 25.08 .2008 \\
2 & E. tatarica & Пермский край, Пермский р-н, с. Бершеть, суходольный луг & 15.08 .2008 \\
3 & E. stricta & Пермский край, окрестности Краснокамска, низинный луг & 24.07 .2008 \\
4 & E. $\times$ reuteri & Пермский край, Добрянский р-н, д. Липово, лесная поляна & 28.07 .2007 \\
5 & E. $\times$ murbeckii & Пермский край, Соликамский р-н, д. Хорюшино, опушка леса & 28.08 .2008 \\
6 & E. brevipila & Пермский край, с. Большая Соснова, опушка леса & 26.07 .2008 \\
7 & E. parviflora & Пермский край, Кудымкарский р-н, д. Качанова, суходольный луг & 16.08 .2008 \\
\hline
\end{tabular}

\section{Обсуждение результатов}

В результате проведенного исследования установлено, что виды рода Euphrasia имеют близкий качественный состав, при идентификации выявлено 16 компонентов (табл. 2 и 3). Главными являются высшие алканы (октадекан, нонадекан, гексакозан, октакозан, нонакозан, эйкозан), а также фитостерин ( $\gamma$-ситостерол) и его предшественник (сквален). Жирные кислоты и их альдегиды обнаружены в небольшом количестве во всех исследованных видах.

Сравнительный анализ показал, что компонентный состав исследуемых видов рода Euphrasia варьирует от трех (E.tatarica) до одиннадцати (E. brevipila) веществ. Компонентный состав E. officinalis, E. stricta и E. parviflora, представлен девятью веществами. По суммарному содержанию идентифицированных липофильных веществ, исследованные виды располагаются в ряду E. stricta $>$ E. brevipila $>$ E. $\times$ murbeckii $>$ E. parviflora $>$ E. officinalis $>$ E. $\times$ reuteri $>$ E. tatarica.

Постоянными и доминирующими компонентами являются высшие алканы, их число в зависимости от вида варьирует от двух до семи соединений, а количественное содержание колеблется в интервале 20,86-60,62\%, в среднем составляет 40,74\%. Наибольшее число компонентов и соответственно максимальное содержание найдено в образце E. brevipila, минимальное число компонентов и наименьшая сумма высших алканов установлено для E. tatarica. Октакозан и нонадекан присутствуют в пяти; гексакозан в четырех; нонакозан и эйкозан - в трех; гептакозан - в двух из семи исследованных видов. Доминирующим по содержанию является нонакозан, его количество колеблется от 14 до 35\%, а минимальное содержание установлено для эйкозана - от 3 до 6,7\%. 
Таблица 2. Суммарное содержание групп БАВ в гексановых извлечениях из растений рода Euphrasia L.

\begin{tabular}{|c|c|c|c|c|c|c|c|c|c|c|c|c|c|c|c|}
\hline \multirow[t]{2}{*}{ № } & \multirow[t]{2}{*}{ Вид } & \multicolumn{2}{|c|}{$\begin{array}{c}\text { Высшие } \\
\text { алканы }\end{array}$} & \multicolumn{2}{|c|}{$\begin{array}{c}\text { Фитосте- } \\
\text { рин и его } \\
\text { предшест- } \\
\text { венник }\end{array}$} & \multicolumn{2}{|c|}{$\begin{array}{c}\text { Альдегиды } \\
\text { насыщен- } \\
\text { ных жир- } \\
\text { ных кислот }\end{array}$} & \multicolumn{2}{|c|}{$\begin{array}{c}\text { Насыщен- } \\
\text { ные жир- } \\
\text { ные кисло- } \\
\text { ты }\end{array}$} & \multicolumn{2}{|c|}{$\begin{array}{l}\text { Ненасы- } \\
\text { щенные } \\
\text { жирные } \\
\text { кислоты }\end{array}$} & \multicolumn{2}{|c|}{$\begin{array}{c}\text { Другие } \\
\text { БАВ }\end{array}$} & \multicolumn{2}{|c|}{ Всего } \\
\hline & & I & II & I & II & I & II & I & II & I & II & I & II & I & II \\
\hline 1 & E.officinalis & 3 & 50,12 & 2 & 3,52 & 2 & 3,91 & 1 & 2,81 & - & - & 1 & 4,22 & 9 & 64,58 \\
\hline 2 & E.tatarica & 2 & 20,86 & 1 & 1,48 & - & $-*$ & - & & - & - & - & - & 3 & 22,34 \\
\hline 3 & E. stricta & 4 & 31,75 & 1 & 28,16 & - & - & 2 & 9,66 & 1 & 15,92 & 1 & 0,27 & 9 & 85,76 \\
\hline 4 & E. $\times$ reuteri & 3 & 40,71 & 2 & 5,64 & - & - & 1 & 1,59 & - & - & - & - & 6 & 47,94 \\
\hline 5 & E. $\times$ murbeckii & 3 & 53,46 & 1 & 10,87 & 2 & 1,01 & - & 5,32 & 1 & 6,04 & - & - & 7 & 76,7 \\
\hline 6 & E.brevipila & 7 & 60,62 & 1 & 21,32 & - & - & - & - & - & - & 3 & 2,38 & 11 & 84,32 \\
\hline 7 & E. parviflora & 4 & 45,63 & 1 & 15,03 & - & - & - & - & 4 & 11,75 & - & - & 9 & 72,41 \\
\hline
\end{tabular}

Примечание: I - количество идентифицированных компонентов; II - содержание идентифицированных компонентов в нормировочных процентах от суммы площадей всех зарегистрированных пиков; * здесь и далее содержание соединения относительно суммы всех пиков менее $0,005 \%$ или его отсутствие.

Таблица 3. Состав гексановых извлечений растений рода Euphrasia L.

\begin{tabular}{|c|c|c|c|c|c|c|c|c|}
\hline \multirow[b]{2}{*}{ Соединение } & \multicolumn{7}{|c|}{ Количественное содержание, \%* } & \multirow[b]{2}{*}{ 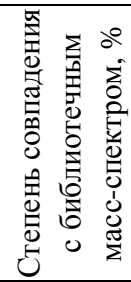 } \\
\hline & 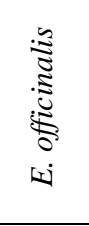 & 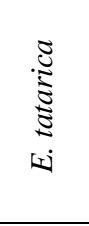 & 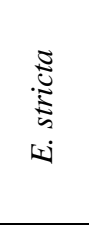 & 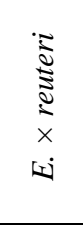 & 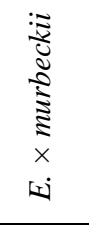 & 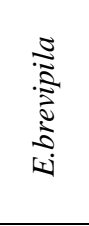 & 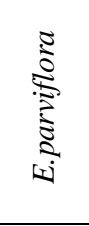 & \\
\hline Неофитадиен & $-* *$ & - & - & - & - & 0,60 & - & 99 \\
\hline Октадекан & - & - & - & 9,45 & - & 1,11 & - & 95 \\
\hline Нонадекан & 9,82 & - & 4,01 & - & 7,78 & 6,89 & 7,34 & 90 \\
\hline Эйкозан & - & 6,62 & - & - & - & 6,71 & 3,10 & 98 \\
\hline Гексакозан & 6,68 & - & 20,90 & - & 38,49 & - & 27,69 & 91 \\
\hline Гептакозан & - & - & - & 9,79 & - & 7,08 & - & 99 \\
\hline Октакозан & 33,62 & - & 6,28 & - & 7,19 & 2,85 & 7,50 & 83 \\
\hline Нонакозан & - & 14,24 & - & 21,47 & - & 35,38 & - & 97 \\
\hline 2-Нонакозанон & - & - & 0,56 & - & - & - & - & 94 \\
\hline Сквален & 1,96 & 1,48 & - & 2,97 & - & - & - & 92 \\
\hline$\gamma$-ситостерол & 1,56 & - & 28,16 & 2,67 & 10,87 & 21,32 & 15,03 & 93 \\
\hline Додекановый (лауриновый) альдегид & 2,05 & - & - & - & 0,59 & - & - & 91 \\
\hline $\begin{array}{l}\text { Тетрадекановый (миристиновый) } \\
\text { альдегид }\end{array}$ & 1,86 & - & - & - & 0,42 & - & - & 95 \\
\hline $\begin{array}{l}\text { Гексадекановая (пальмитиновая) } \\
\text { кислота }\end{array}$ & 2,81 & - & 7,75 & 1,59 & 5,32 & - & 10,05 & 93 \\
\hline Октадекановая (стеариновая) кислота & - & - & 1,91 & - & - & - & - & 91 \\
\hline $\begin{array}{l}\text { 9,12-октадекадиеновая (линолевая) } \\
\text { кислота }\end{array}$ & - & - & - & - & - & - & 1,91 & 99 \\
\hline $\begin{array}{l}\text { 9,12,15-октадекатриеновая } \\
\text { (линоленовая) кислота }\end{array}$ & - & - & 15,92 & - & 6,04 & - & 6,93 & 93 \\
\hline 9-октадеценовая (олеиновая) кислота & - & - & - & - & - & - & 2,91 & 86 \\
\hline Тиомочевина & 4,22 & - & - & - & - & - & - & 80 \\
\hline $\begin{array}{l}\text { 6,10,14-триметил-2-пентадеканон } \\
\text { (гексагидрофарнезил-ацетон) }\end{array}$ & - & - & 0,27 & - & - & 0,48 & - & 97 \\
\hline $\begin{array}{l}\text { 1,2-Бензолдикарбоновая (фталевая) } \\
\text { кислота }\end{array}$ & - & - & - & - & - & 0,66 & - & 97 \\
\hline Фитол & - & - & - & - & - & 1,24 & - & 91 \\
\hline
\end{tabular}

Примечания. " содержание компонентов в нормировочных процентах от суммы площадей всех зарегистрированных пиков; ** содержание соединения относительно суммы всех пиков менее $0,005 \%$ или его отсутствие.

Во всех видах, за исключением E. tatarica, присутствует $\gamma$-ситостерол $(1,56-28,16 \%)$. В образцах E. officinalis и E. $\times$ reuteri данное соединение накапливается в небольшом количестве, 1,56 и 2,67\% соответственно. При этом установлено, что данные виды характеризуются присутствием сквалена - природного ациклического тритерпена $\left(\mathrm{C}_{30} \mathrm{H}_{30}\right)$ с 6 двойными связями. Сквален выполняет в организме роль регулятора липидного и стероидного обмена и представляет интерес как вещество с выраженной антиоксидантной активностью [11]. 
В составе гексанового извлечения из растений рода Euphrasia обнаружено пять жирных кислот. Доминирующими являются ненасыщенные - их суммарное содержание, в зависимости от вида, колеблется от 6,07 до $15,92 \%$. Сумма насыщенных жирных кислот у разных видов варьирует от 1,59 до 9,66\%. Среди ненасыщенных кислот преобладает линоленовая (среднее значение для рода Euphrasia - 9,63\%), среди насыщенных - пальмитиновая (среднее значение для рода Euphrasia - 5,8\%).

Для всех исследуемых образцов, за исключением E. tatarica и E. brevipila, характерно накопление пальмитиновой кислоты, тогда как стеариновая кислота обнаруживается только у E. stricta. Незаменимые (эсенциальные) жирные кислоты обнаружены в E. stricra (линоленовая -15,92\%), E. × murbecki (линоленовая $-6,04 \%$ ) и E. parviflora (линолевая $-1,93 \%$, линоленовая $-6,93 \%$ ). Компонентный состав E. officinalis и $E . \times$ murbeckii характеризуется присутствием альдегидов насыщенных жирных кислот - лауриновым и миристиновым.

Специфическими компонентами липофильных извлечений растений рода Euphrasia являются тиомочевина (E. officinalis), фитол, фталевая кислота (E. brevipila) и гексагидрофарнезилацетон (E. ${ }^{\circ}$ brevipila, E. stricra), их содержание не превышает 5\%.

\section{Выводы}

Липофильные вещества растений рода Euphrasia имеют близкий качественный состав, представленный 16 компонентами. Доминирующими являются высшие алканы, а также $\gamma$-ситостерол и его предшественник - сквален. Жирные кислоты и их альдегиды обнаружены в небольшом количестве во всех исследованных видах. По суммарному содержанию идентифицированных липофильных веществ исследованные виды располагаются в ряду E. stricta $>$ E. brevipila > E. $\times$ murbeckii $>$ E. parviflora $>$ E. officinalis > E. $\times$ reuteri $>$ E tatarica.

\section{Список литературы}

1. Флора СССР / под ред. Б.К. Шишкина. М.; Л., 1955. Т. 22. 705 с.

2. Поляковская М. Лесные лекарственные растения. Варшава, 1986. 251 с.

3. Энциклопедический словарь лекарственных растений и продуктов животного происхождения / под ред. Г.П. Яковлева, К.Ф. Блиновой. СПб., 1999. 407 с.

4. Растительные ресурсы СССР: Цветковые растения, их химический состав, использование. Семейства Caprifoliaceae - Plantaginaceae. Л., 1990. 362 c.

5. Петриченко В.М., Сухинина Т.В. Очанки западного Урала (фармакогностические и биологические аспекты). Пермь, 2006. 145 с.

6. Петриченко В.М., Сухинина Т.В., Бабиян Л.К. Химический состав и антиоксидантная активность биологически активных веществ очанки коротковолосистой // Химико-фармацевтический журнал. 2006. Т. 40, №6. C. 22-26.

7. Goun E.A., Petrichenko V.M., Solodnikov S.U. Anticancer and antithrombin activity of Russian plants // Journal of Ethnopharmacology. 2001. N81. Pp. 337-342.

8. Кретович В.Л. Биохимия растений. М., 1980. 445 с.

9. Deng Yu Cheng, Hua Hui Ming, Li Jun. Lapinskas // Economic Botany. 2001. Vol. 55, N1. Pp. 83-91.

10. Awaisheh S.S., Khalifeh M.S., Al-Ruwaili M.A., Khalil O.M., Al-Ameri O.H., Al-Groom R. Effect of supplementation of probiotics and phytosterols alone or in combination on serum and hepatic lipid profiles and thyroid hormones of hypercholesterolemic rats // Journal of dairy science. 2013. Vol. 96, N1. Pp. 9-15.

11. He H.P., Cai Y., Sun M. Extraction and purification of squalene from amaranthus grain // Journal of Agricultural and Food Chemistry. 2002. Vol. 50, N2. Pp. 368-372. 
Krotkova O.A., Bombela T.V., Petrichenko V.M. COMPARATIVE STUDY OF LIPOPHILIC SUBSTANCES OF PLANTS FROM THE GENUS EUPHRASIA L.

Perm State Pharmaceutical Academy, Polevaia st., 2, Perm, 614990 (Russia), e-mail: tatyana.bombela@yandex.ru

Composition of lipophilic substances extracted with hexane in herb of E. officinalis L., E. tatarica Fisch., E. stricta D. Wolff. ex J.F.Lehm., E. x reuteri Wettst., E. x murbeckii Wettst., E. brevipila Burnat et Gremli, E. parviflora Schag., growing in Perm Krai has been studied by gas-liquid chromatography (GLC) method. Lipophilic substances have been identified: octadecane, nonadecane, eicosane, hexacosane, heptacosane, octacosane, nonacosane, 2-nonacosanol, neophytadiene, lauric aldehyde, myristic aldehyde, palmitic acid, stearic acid, linoleic acid, linolenoic acid, oleic acid, $\gamma$-sitosterol, squalene, hexahydrofarnesylacetone, phthalic acid. Dominating components of lipophilic complex are high alkanes, $\gamma$-sitosterol and squalene. Fatty acids and its aldehydes were found in small amounts in all species of Euphrasia.

Keywords: GC/MS, lipophilic substances, Euphrasia.

\section{References}

1. Flora SSSR. [Flora of the USSR]. Ed. B.K. Shishkin. Moscow; Leningrad, 1955, vol. 22, 705 p. (in Russ.).

2. Poliakovskaia M. Lesnye lekarstvennye rasteniia. [Forest herbs]. Warsaw, 1986, 251 p. (in Russ.).

3. Entsiklopedicheskii slovar' lekarstvennykh rastenii i produktov zhivotnogo proiskhozhdeniia. [Encyclopedic Dictionary of medicinal plants and products of animal origin]. Ed. G.P. Iakovlev, K.F. Blinova. St. Petersburg, 1999, 407 p. (in Russ.).

4. Rastitel'nye resursy SSSR: Tsvetkovye rasteniia, ikh khimicheskii sostav, ispol'zovanie. Semeistva Caprifoliaceae Plantaginaceae. [Plant Resources of the USSR: Flowering plants, their chemical composition and utilization. Family Caprifoliaceae - Plantaginaceae]. Leningrad, 1990, 362 p. (in Russ.).

5. Petrichenko V.M., Sukhinina T.V. Ochanki zapadnogo Urala (farmakognosticheskie i biologicheskie aspekty). [Eyebright western Urals (Farmakognostichesky and biological aspects)]. Perm, 2006, 145 p. (in Russ.).

6. Petrichenko V.M., Sukhinina T.V., Babiian L.K. Khimiko-farmatsevticheskii zhurnal, 2006, vol. 40, no. 6, pp. 22-26. (in Russ.).

7. Goun E.A., Petrichenko V.M., Solodnikov S.U. Journal of Ethnopharmacology, 2001, no. 81, pp. 337-342.

8. Kretovich V.L. Biokhimiia rastenii. [Biochemistry of plants]. Moscow, 1980, 445 p. (in Russ.).

9. Deng Yu Cheng, Hua Hui Ming, Li Jun. Economic Botany, 2001, vol. 55, no. 1, pp. 83-91.

10. Awaisheh S.S., Khalifeh M.S., Al-Ruwaili M.A., Khalil O.M., Al-Ameri O.H., Al-Groom R. Journal of dairy science, 2013, vol. 96, no. 1, pp. 9-15.

11. He H.P., Cai Y., Sun M. Journal of Agricultural and Food Chemistry, 2002, vol. 50, no. 2, pp. 368-372.

Received March 4, 2013

\footnotetext{
* Corresponding author.
} 
